\title{
ANALISIS SISTEM TANDA DI PUSAT PERBELANJAAN BERDASARKAN SEMIOTIKA CHARLES SANDERS PEIRCE
}

\author{
Riana Hoseani ${ }^{1}$, Fenti Mariska Yohana ${ }^{2}$ \\ Program Studi Desain Komunikasi Visual, Universitas Indraprasta PGRI
}

\begin{abstract}
Abstrak. Upaya menggunakan tanda-tanda visual berangkat dari pemahaman bahwa bahasa visual memiliki karakteristik khas yang dapat menimbulkan efek ketertarikan para pengamatnya. Hal seperti ini terkadang sulit disampaikan dengan bahasa verbal semata. Dalam studi ini, penulis meneliti tanda-tanda visual yang sering ditemukan pada pusat perbelanjaan. Kehadiran sistem tanda di ruang publik tersebut akan dianalisis menggunakan semiotika. Semiotika yang dipilih sebagai kerangka teoretis adalah semiotika Charles Sanders Peirce. Dalam Semiotika Peirce, semiotika didasarkan pada logika, karena logika mempelajari bagaimana orang bernalar, sedangkan penalaran dilakukan melalui tanda-tanda. Tujuan penelitian ini adalah menggali arti dari sistem tanda yang terdapat pada pusat perbelanjaan melalui semiotika Peirce.
\end{abstract}

Kata kunci: pusat perbelanjaan, semiotika Peirce, sistem tanda.

\begin{abstract}
The effort to use visual signs departs from the understanding that visual language has distinctive characteristics that can create an attraction effect on its observers. Such a thing is sometimes difficult to convey only in verbal language. In this study, the authors examined visual signs that were found frequently in shopping centers. The presence of the sign system in public space was analyzed using semiotics. The kind of semiotics chosen as the theoretical framework was semiotics of Charles Sanders Peirce. According to Peirce theory, semiotics is based on logic, because logic studies how people make a reasoning, while the reasoning itself is carried out through signs. The aim of this study is to reveal the meaning of the sign system in shopping centers through Peirce semiotics.
\end{abstract}

Keywords: shopping center, Peirce semiotics, sign system.

Correspondence author: Fenti Mariska Yohana, fentiyohana113@gmail.com, Depok, Indonesia

\section{PENDAHULUAN}

Manusia, sebagai makhluk sosial, berinteraksi dengan sesamanya secara langsung maupun melalui perantaraan alat bantu, seperti telepon dan media sosial. 
Unsur-unsur perantara komunikasi manusia yang yang utama dapat berupa huruf, kata-kata, hingga air muka dan gerak tubuh lawan bicara yang ditampilkan dalam kegiatan berkomunikasi. Pada dasarnya, segala hal yang memerantarai komunikasi tersebut merupakan tanda (sign) - isyarat, semboyan, papan penunjuk jalan, pertanda, pengenal, petanda, lampu, papan arah, pratanda, gelagat, dan sebagainya-baik berbentuk verbal maupun visual.

Komunikasi verbal dan non verbal. Komunikasi verbal adalah simbol atau pesan verbal adalah semua jenis simbol yang menggunakan satu kata atrau lebih. Komunikasi non verbal adalaah komunikasi yang bukan berupa kata-kata, tidak hanya bahasa tubuh tetapi juga gambar dan atau semua aspek perubahan, perubahan suara, warna suara, volume. Aspek lingkungan yang memengaruhi interaksi juga termasuk komunikasi non verbal. Seperti dikutip dari buku Interpersonal - Interaksi keseharian, para peneliti berestimasi bahwa perilaku non verbal memengaruhi 65\%-93\% makna komunikasi (Maydi \& Esfaandiari, 2018).

Komunikasi nonverbal harus menggunakan media atau instrumen agar pesan yang disampaikan dapat dimengerti. Sementara itu, komunikasi tanpa tatap muka juga sering dilakukan oleh hampir setiap orang. Komunikasi tanpa tatap muka dapat dilakukan dengan menggunakan alat-alat bantu atau media penyampai pesan, seperti percakapan melalui telepon, surat-menyurat, maupun iklan-iklan di televisi, banner, poster.

Media budaya berkembang sejak abad 21 dimana manusia menerima dan menggunakan teknologi yang awalnya sederhana hingga teknologi canggih saat ini. Bentuk teknologi yang sudah ada sekitar kita semua selama ini ada diantaranya radio, telepon, televisi, film, komputer, hingga jaringan internet. Menurut Christomy dan Yuwono (2010: 182) benda-benda dan teknologi semacam itu dapat disebut sebagai media budaya, suatu media bagi teknologi yang berada pada kebudayaan manusia, dan media itu digunakan oleh manusia atau masyarakat untuk menunjukkan "kekuatannya" pada masyarakat konsumtif.

Dewasa ini, dengan perkembangan teknologi komunikasi yang ada, komunikasi visual nampaknya menjadi salah satu modus komunikasi paling penting. Bahasa, sebagai alat utama penyampai pesan yang efektif, pada akhirnya harus dapat divisualisasikan oleh seorang perancang atau desainer komunikasi visual. Dengan kata lain, seorang desainer komunikasi visual harus benar-benar memahami pesan-pesan yang ingin disampaikannya. Ia juga harus mampu menafsirkan kecenderungan dan kondisi si penerima pesan, baik kondisi fisik maupun psikologisnya. Dalam hal ini, ia pun harus mampu memilih jenis dan gaya bahasa yang serasi sehingga mudah diterima dan dimengerti, serta secara tepat dan efektif menyampaikan pesan kepada penerima yang disasar.

Colin Cherry (dalam Ambar: 2017), Komunikasi adalah usaha untuk membuat satuan sosial dari individu dengan menggunakan bahasa atau tanda. Dan juga memiliki serangkaian peraturan untuk berbagai kegiatan mencapai tujuan.

Bagi Peirce sendiri tanda-tanda visual yang sempurna yaitu diantaranya tanda yang bisa menyeimbangkan iconic, symbolic, and indexical. Gagasan Peirce yang mendasar adalah pemecahan tanda dalam struktur secara visual (Budiman, 4:2005). Semiotik tanda yang diusung Peirce membuka jalan bagi media gambar untuk dianalisis dengan metode Peirce tanda yang berupa iconic, symbolis, and indexical. Semiotik berfungsi sebagai alat analisis yang diutarakan oleh Hidayat (dalam Christomy dan 
Yuwono, 2004: 77) dimana Semiotik dapat dimanfaatkan oleh berbagai bidang ilmu diantaranya arsitektur, kedokteran, sinematografi, linguistik, kesusastraan bahkan Hukum dan Antropologi dalam memahami tanda agar menjadi jelas dan tidak bias.

Gambar, sebagai salah satu media bagi komunikasi visual, terbentuk atas unsurunsur rupa seperti garis, warna, dan komposisi. Gambar dapat dikategorikan ke dalam bahasa komunikasi nonverbal, berbeda dengan wujud bahasa tulisan maupun ucapan. Namun demikian, dalam perkembangannya, tulisan pun kerap dikembangkan menjadi rancang grafis dalam komunikasi visual yang banyak memanfaatkan daya dukung gambar guna mengefektifkan komunikasi.

Kebutuhan akan penggunaan tanda-tanda visual berangkat dari realitas bahwa bahasa visual memiliki karakteristik khas yang dapat menimbulkan efek ketertarikan para pengamatnya. Karakteristik ini membantu pengomunikasian hal-hal yang biasanya sulit disampaikan hanya dengan bahasa verbal.

We learn from semiotics that we live in a world of signs and we have no way of understanding anything except through signs and the codes into which they are organized. Through the study of semiotics, we become aware that these signs and codes are normally trasnparent and disguise our task in reading them (Chandler, 30: 2002). Jadi, dengan mempelajari semiotik, kita sadar akan tanda dan simbol yang penuh makna, sehingga dapat dibaca. Secara sederhana istilah semiotika dapat dijelaskan sebagai ilmu yang mengkaji tentang tanda dan makna tanda. Tanda itu sendiri merupakan basis dari seluruh komunikasi. Suatu tanda akan menandakan sesuatu selain dirinya sendiri.

Dalam tulisan ini, penulis akan mendiskusikan sistem tanda yang terekspresikan dalam bahasa visual. Tanda-tanda yang akan dianalisis merupakan bagian dari sistem tanda yang sering ditemukan pada pusat perbelanjaan. Semiotika yang digagas oleh Charles Sanders Peirce akan dimanfaatkan sebagai kerangka teoretis untuk menganalisis sistem tanda tersebut.

\section{METODOLOGI PENELITIAN}

Penelitian ini menggunakan pendekatan kualitatif, di mana data primer dikumpulkan melalui observasi dalam latar alamiahnya - dalam hal ini, sistem tanda pada pusat perbelanjaan diamati pada konteks aktualnya. Ada beberapa tahapan yang dilakukan dalam penelitian ini. Pertama, pengumpulan data, baik dari sumber-sumber primer maupun sekunder. Data primer diperoleh melalui pengamatan langsung terhadap sistem tanda yang kerap ditemukan di pusat-pusat perbelanjaan di wilayah Jakarta dan sekitarnya. Adapun data sekunder diperoleh dari berbagai literatur yang memiliki relevansi dengan penelitian, khususnya literatur yang mendiskusikan sistem tanda. Kedua, melakukan analisis semiotik terhadap sistem tanda yang terdapat pada pusat perbelanjaan dengan menggunakan klasifikasi tanda yang digagas Peirce sebagai pisau analisis. Ketiga, penarikan kesimpulan dari hasil analisis sistem tanda di pusatpusat perbelanjaan dengan menggunakan pendekatan semiotika Peirce. 


\section{HASIL DAN PEMBAHASAN}

\section{Semiotika Peirce}

Istilah semiotika berasal dari bahasa Yunani "semeion" yang berarti tanda (sign). Semiotika merupakan disiplin ilmu yang menganalisis dan mengkaji tanda-tanda pada suatu objek agar makna yang terdapat dalam objek tersebut dapat diketahui dan dipahami-atau secara sederhana, ilmu tentang tanda. Selain berusaha menjelaskan bagaimana tanda mampu menyampaikan makna, semiotika juga menyelisik semua hubungan di antara keduanya, hubungan satu tanda dengan tanda lain, serta pengiriman dan penerimaan tanda dalam suatu komunikasi.

Menurut sejarahnya, ilmu semiotika sudah dikenal sejak akhir abad ke-19, namun baru berkembang pada abad ke-20. Pada mulanya semiotika merupakan bagian dari ilmu filsafat, kemudian meluas dan dikenal dalam dunia sastra dan bahasa. Dewasa ini semiotika juga merambah ke dunia seni, khususnya seni rupa.

Secara terminologis, semiotik adalah cabang ilmu yang berurusan dengan dengan pengkajian tanda dan segala sesuatu yang berhubungan dengan tanda, seperti sistem tanda dan proses yang berlaku bagi tanda (van Zoest \& Sudjiman, 1993:1). Semiotik merupakan ilmu yang mempelajari sederetan luas obyek-obyek, peristiwaperistiwa, seluruh kebudayaan sebagai tanda.

Tanda sendiri senantiasa kita temui dalam hidup keseharian, baik dalam bentuk tulisan, suara, maupun visual. Semiotika berusaha membangun pemahaman tentang bagaimana tanda mewakili konsep, ide, situasi, keadaan, perasaan, dan hal-hal lain yang berada di luar tanda itu sendiri-dengan kata lain, tanda dan makna yang dibawanya terkait satu sama lain secara mana suka (arbitrary).

Metode semiotika pada dasarnya bersifat kualitatif-deskriotif (interpretation), yaitu sebuah metode yang memfokuskan dirinya pada "tanda" dan "teks" sebagai objek kajian, serta bagaimana peneliti menafsirkan dan memahami kode (decoding) di balik tanda dan teks tersebut (Christomy dan Yuwono, 99: 2004). Maka semiotika sebagai ilmu makna dan tanda mampu meng-interpretasikan tanda berupa teks.

Menurut Charles Sander Peirce, semiotika didasarkan pada logika, mengingat penalaran senantiasa dilakukan melalui tanda-tanda. Dalam Gorlee (1994:2) Peirce pun menceritakan secara rinci dengan nama semiosis. Semiosis merupakan tanda yang diusung Peirce bertujuan sebagai penyampai maksud sehingga terjadi komunikasi didalamnya. Tanda-tanda memungkinkan kita berpikir, berhubungan dengan orang lain, dan memberi makna pada apa yang ditampilkan oleh alam semesta. Peirce berpandangan bahwa keberadaan tanda-tanda selalu memiliki keterkaitan dengan tanda-tanda lain karena adanya ikatan konvensional di antara tanda-tanda tersebuthal inilah yang memungkinkan penyampaian makna oleh tanda.

Jenis-jenis tanda yang dikenal manusia beraneka ragam. Di antara tanda-tanda tersebut, tanda linguistik merupakan salah satu yang terpenting. Berangkat dari arti penting tanda bagi kehidupan manusia, fungsi dan kegunaan suatu tanda kemudian menjadi pusat perhatian dalam kajian semiotika.

Peirce sendiri kemudian membuat klasifikasi atas tanda-tanda yang kita jumpai dalam kehidupan sehari-hari. Berdasarkan klasifikasi Peirce dalam teori semiotikanya, terdapat sepuluh macam tanda, yaitu: 
1. Qualisign, merujuk pada kualitas dari suatu tanda. Misalnya, ketika seseorang berbicara dengan suara keras atau nada meninggi, maka orang lain akan dapat mengetahui bahwa ia sedang marah; ketika seseorang tertawa, maka orang lain akan dapat mengetahui bahwa ia sedang bahagia. Contoh lain, ketika warna merah menunjukkan keberanian, warna putih menunjukkan kesucian, sementara warna hitam menunjukkan kejahatan.

2. Inconic Sinsign, yakni tanda yang menunjukkan suatu kemiripan dengan objek yang dirujuknya. Misalnya, foto dan peta.

3. Rhematic Indexical Sinsign, yakni tanda yang berkaitan dengan pengalaman langsung, di mana keberadaannya disebabkan oleh suatu hal. Misalnya, pada jalur jalan raya yang sering memakan korban akibat kecelakaan lalu lintas, dipasang tanda tengkorak yang kadang kala disertai dengan informasi mengenai jumlah korban kecelakaan di tempat tersebut. Tanda ini menandakan jalur berbahaya, dipasang dengan tujuan agar para pengguna jalan yang melintasinya lebih berhatihati.

4. Dicent Sinsign, yakni tanda yang menunjukkan informasi tentang suatu hal. Misalnya, rambu lalu lintas bergambar masjid atau tempat pengisian bahan bakar (SPBU), menandakan bahwa tidak jauh dari tempat tersebut terdapat masjid atau SPBU.

5. Iconic Legisign, yakni tanda yang berupa perintah atau larangan, erat kaitannya dengan norma atau hukum. Misalnya, lampu lalu lintas yang berwarna merah memberikan perintah bagi pengendara untuk berhenti, sementara yang berwarna hijau memberikan perintah untuk jalan; rambu lalu lintas bergambar huruf "P" yang dicoret menunjukkan larangan untuk memarkir kendaraan.

6. Rhematic Indexical Legisign, yakni tanda yang merujuk pada objek tertentu. Misalnya, gambar siluet pada toilet yang menunjukkan mana toilet untuk pria, mana toilet untuk wanita.

7. Dicent Indexical Legisign, yakni tanda yang merujuk pada subjeknya untuk memberitahukan suatu informasi tertentu. Misalnya, ketika sebuah mobil di pinggir jalan menyalakan lampu hazard, maka lampu tersebut menunjukkan bahwa mobil itu sedang mengalami masalah.

8. Rhematic Symbol atau Symbolic Rheme, yakni tanda yang menunjukkan keterkaitan dengan objek yang terasosiasi dan secara umum disepakati. Misalnya, ketika melihat gambar mobil, kita mengatakan bahwa itu gambar mobil dan orang lain pun demikian, mengatakan hal yang sama.

9. Dicent Symbol atau Proposition, adalah tanda yang secara langsung menghubungkan antara objek dengan penangkapan otak. Misalnya, ketika seseorang menyuruh kita untuk keluar dari ruangan, maka kita langsung melangkah keluar. Hal ini menunjukkan bahwa tanda tersebut terhubung langsung dengan penangkapan otak kita menjadi sebuah perintah yang kita laksanakan.

10. Argument, yakni tanda yang merupakan pendapat hasil berpikir seseorang berdasarkan suatu pertimbangan atau alasan tertentu. Misalnya, ketika seseorang mengatakan bahwa ruangan yang ia masuki memiliki penataan yang "berkelas." Maka, pernyataan "berkelas" di sini merupakan pendapat yang didukung oleh berbagai pertimbangan, seperti pencahayaan, pemilihan perabot dan penempatannya, serta pertimbangan-pertimbangan lain sehingga menurutnya ruangan itu memang "berkelas." 
Klasifikasi tanda menurut Peirce di atas akan digunakan di dalam pembahasan tulisan ini untuk mengidentifikasi dan menjelaskan sistem-sistem tanda yang dijumpai pada pusat perbelanjaan. Namun demikian, sebagai sebuah kajian empiris, tulisan ini tidak bermaksud menemukan contoh bagi kesemua kategori tanda tersebut. Dengan demikian, kategori yang digunakan hanya mencakup kategori-kategori yang memang kerap ditemui manifestasi tandanya pada pusat-pusat perbelanjaan di lokus penelitian, yakni Jakarta dan kota-kota satelit di sekitarnya.

\section{Pembahasan}

Sebagaimana halnya ruang-ruang publik di lingkungan perkotaan pada umumnya, suatu pusat perbelanjaan sudah sewajarnya difasilitasi dengan tanda-tanda. Hal ini, di satu sisi, dimaksudkan untuk memudahkan orang-orang yang mengunjunginya melakukan berbagai aktivitas di tempat tersebut. Di sisi lain, keberadaan tanda-tanda juga akan membuat para pengunjung lebih sadar dan perhatian atas perilaku yang patut atau tidak patut untuk dilakukan di ruang publik yang tengah ia kungjungi.

Tanda-tanda yang bertebaran di pusat perbelanjaan, banyak di antaranya berupa bahasa visual dalam bentuk gambar. Kerap kali gambar-gambar ini disertai dengan kalimat-kalimat atau kata-kata sebagai pengungkapan makna melalui bahasa verbal, namun tidak selalu. Berdasarkan semiotika Peirce, penulis mengidentifikasi berbagai sistem tanda yang ada di pusat perbelanjaan dan menganalisisnya berdasarkan klasifikasi tanda yang digagas Peirce. Berikut akan ditampilkan beberapa contoh tanda yang kerap dijumpai di pusat-pusat perbelanjaan.

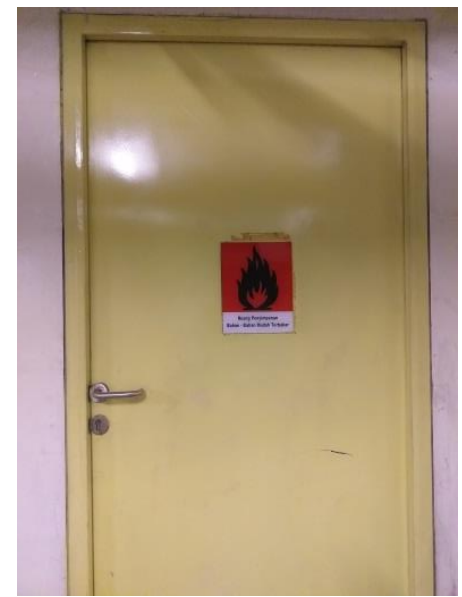

Sumber: dokumentasi pribadi, 10 Desember 2020

Gambar di atas memperlihatkan sebuah tanda dengan visualisasi api yang disertai dengan keterangan "Ruang Penyimpanan Bahan-Bahan Mudah Terbakar." Dalam klasifikasi Peirce, sistem tanda di atas dapat digolongkan sebagai Dicent Sinsign - tanda tersebut menunjukkan informasi tentang suatu hal, yaitu sebuah ruang yang di dalamnya berisi bahan-bahan mudah terbakar. Tanda lain dengan klasifikasi serupa dapat kita temui pada gambar di bawah ini: 


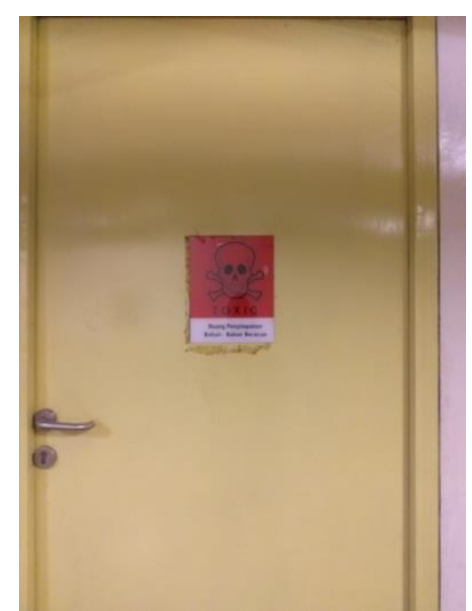

Sumber: dokumentasi pribadi, 10 Desember 2020

Gambar di atas menampilkan sebuah tanda dengan visualisasi tengkorak yang disertai tulisan "TOXIC" dan "Ruang Penyimpanan Bahan-Bahan Beracun." Tanda tersebut menginformasikan bahwa di balik pintu tersimpan bahan-bahan beracun. Sebagaimana tanda sebelumnya, tanda ini juga dapat diklasifikasikan sebagai Dicent Sinsign. Menariknya, kedua tanda tersebut, tanda api dan tanda tengkorak, mengimplikasikan sebuah peringatan agar para pengunjung berhati-hati, serta larangan bagi para pengunjung untuk tidak memasuki ruangan tersebut. Dengan demikian, tanda-tanda tersebut juga mengandung aspek-aspek yang umumnya dimiliki Rhematic Indexical Legisign. Hal ini juga terkait erat dengan penggunaan warna merah untuk menunjukkan sesuatu yang berbahaya. Dengan demikian, selain Dicent Sinsign dan Rhematic Indexical Legisign, kedua tanda tersebut memiliki aspek Qualisign.

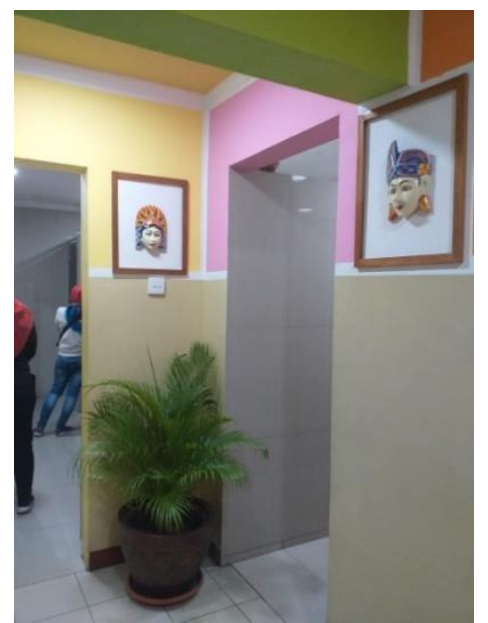

Sumber: dokumentasi pribadi, 10 November 2020

Gambar di atas memperlihatkan tanda dalam bentuk topeng wayang wanita dan pria. Penempatannya adalah pada pintu masuk toilet yang terdapat di sebuah pusat perbelanjaan. Melalui tanda tersebut, para pengunjung bisa dengan mudah membedakan mana toilet wanita dan mana toilet pria. Dalam klasifikasi Peirce, tanda ini dapat dikategorikan sebagai Rhematic Indexical Legisign - bukan hanya merujuk pada objek tertentu untuk membedakannya dengan objek lain (toilet wanita dan toilet pria), 
tanda yang digunakan sekaligus mengimplikasikan aturan atau larangan (pria hanya boleh menggunakan toilet pria dan dilarang menggunakan toilet wanita, dan sebaliknya).

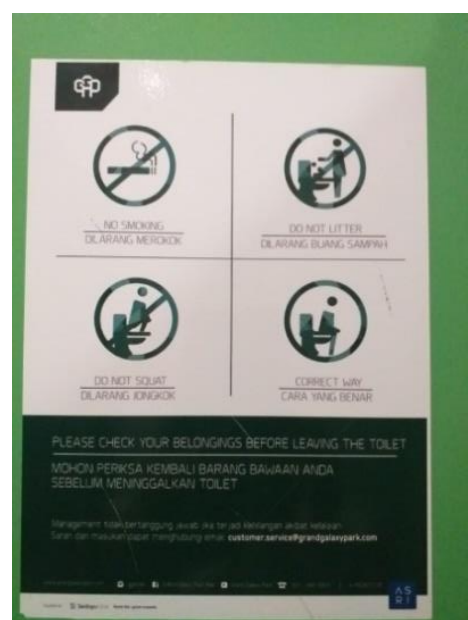

Sumber: dokumentasi pribadi, 29 November 2020

Gambar di atas memperlihatkan beberapa tanda yang menunjukkan larangan, yakni "dilarang merokok," "dilarang buang sampah di kloset," dan "dilarang jongkok pada toilet," serta sebuah tanda yang menunjukkan cara duduk yang benar pada toilet. Sistem tanda di atas menunjukkan perilaku atau tindakan yang tidak boleh dan yang disarankan untuk dilakukan di suatu ruangan yang spesifik, yakni toilet. Di dalam toilet, pengunjung tidak boleh merokok, tidak boleh membuang sampah ke dalam kloset, serta harus mengikuti aturan yang benar pada saat menggunakan toilet. Oleh karena berisikan perintah atau larangan, tanda-tanda tersebut dapat dikategorikan sebagai Iconic Legisign.

Di saat yang bersamaan, sistem tanda di atas juga dapat dikategorikan sebagai Qualisign. Qualisign merujuk pada kualitas dari suatu tanda. Tanda dilarang merokok memiliki kualitas yang mampu memengaruhi pengunjung agar tidak merokok di dalam toilet. Tanda dilarang buang sampah memiliki kualitas yang mampu memengaruhi pengunjung agar tidak membuang sampah di kloset. Sebagai sebuah sistem, tanda tersebut terhubung dengan keberadaan tempat sampah yang telah disediakan oleh pengelola pusat perbelanjaan di dalam toilet, sehingga para pengunjung tahu di mana harus membuang sampah mereka. Demikian pula kedua tanda terakhir, memiliki kualitas yang mampu memengaruhi pengunjung untuk menggunakan toilet dengan cara yang benar, sekaligus untuk tidak berjongkok di toilet. 


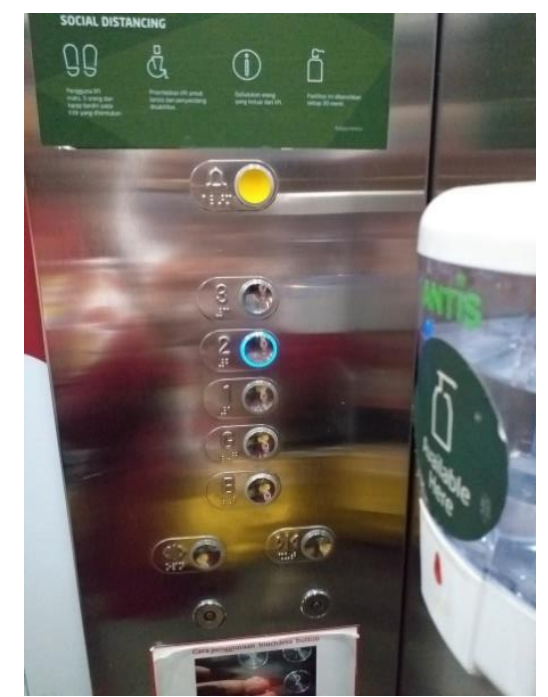

Sumber: dokumentasi pribadi, 29 November 2020

Gambar di atas memperlihatkan sebuah sistem tanda yang terdapat di dalam sebuah lift. Pada sistem tanda tersebut, terdapat tanda yang divisualisasikan dengan gambar telapak kaki, menandakan bahwa semua pengguna lift harus menjaga jarak satu sama lain; tanda pengguna kursi roda, menandakan bahwa para pengguna lift harus memberikan prioritas bagi penyandang disabilitas; tanda berupa gambar seperti pintu terbuka, menandakan perlunya mendahulukan orang-orang yang keluar dari lift; serta tanda berupa gambar alat penyemprot, menandakan bahwa fasilitas lift tersebut dibersihkan setiap 30 menit. Dalam klasifikasi Peirce, sistem tanda tersebut dapat dikategorikan sebagai Dicent Indexical Legisign, karena merujuk pada subjeknya atas suatu informasi tertentu. Informasi yang hendak disampaikan berkenaan dengan kondisi pandemi Covid-19, sehingga mengimplikasikan perlunya para pengunjung yang menggunakan lift untuk melakukan penjarakan sosial-hal mana dikuatkan dengan adanya tulisan "SOCIAL DISTANCING."

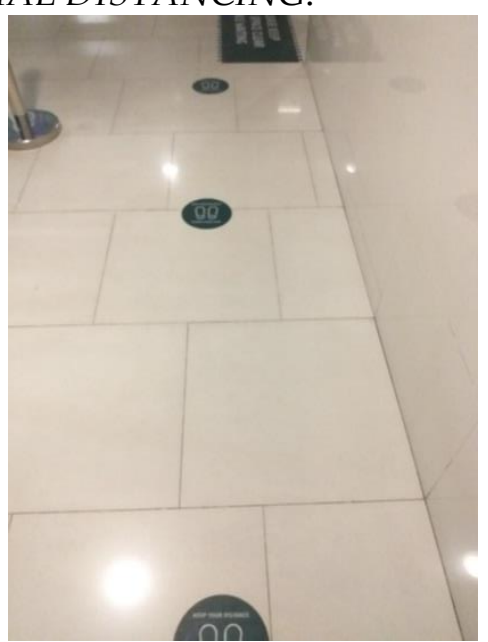

Sumber: dokumentasi pribadi, 29 November 2020

Pada gambar di atas, terlihat adanya tanda di lantai berupa gambar telapak kaki yang ditempatkan secara berjarak. Tanda ini juga harus dipahami dalam konteks 
kondisi pandemi Covid-19 yang mengharuskan setiap pelanggan untuk menjaga jarak, yaitu 1-2 meter. Dalam klasifikasi Peirce, tanda ini dapat dikategorikan sebagai Dicent Symbol atau Proposition, karena secara langsung menghubungkan antara objek tertentu dengan penangkapan otak. Bahwa dengan melihat tanda tersebut, para pengunjung dapat langsung mengambil tindakan menjaga jarak antrean dengan pelanggan lain.

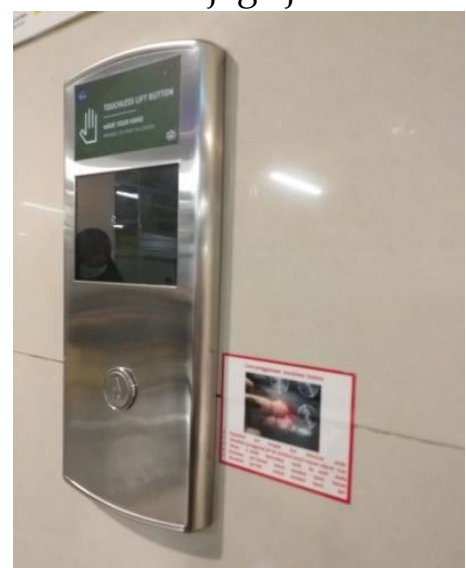

Sumber: dokumentasi pribadi, 29 November 2020

Gambar di atas memperlihatkan sebuah tanda yang divisualisasikan dengan gambar tangan, menginformasikan bahwa lift yang ditandainya dapat dioperasikan secara "touchless" (tanpa disentuh). Tanda ini memberitahukan kepada para pengunjung bahwa lift tersebut harus diakses dengan tidak menyentuh tombolnya-lift tersebut memiliki sistem sensor sehingga mampu menutup dengan sendirinya. Tanda ini dipasang agar para pengunjung dapat meminimalisasi kontak atau sentuhan dengan benda-benda yang ada di pusat perbelanjaan, sehingga membantu mencegah penularan penyakit Covid-19. Pada tanda tersebut, sesuai dengan klasifikasi Peirce, kita dapati adanya Iconic Sinsign, berupa kemiripan gambar tangan dengan pesan yang diinformasikan, yakni "touchless."

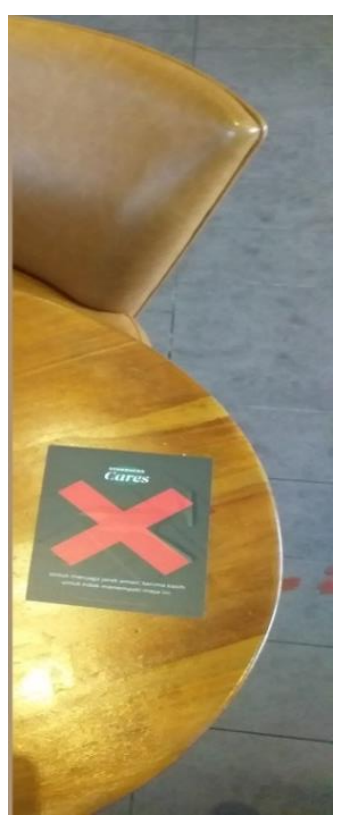

Sumber: dokumentasi pribadi, 16 Desember 2020 
Gambar di atas memperlihatkan adanya sebuah tanda silang berwarna merah pada meja di sebuah kedai kopi yang ada di pusat perbelanjaan. Tanda silang tersebut juga disertai dengan tambahan keterangan: "untuk menjaga jarak aman, terima kasih." Tanda ini menginformasikan kepada para pengunjung bahwa bangku tersebut merupakan bangku yang tidak boleh diduduki, sekaligus menginformasikan perlunya untuk tetap menjaga jarak dengan pengunjung lain. Dengan demikian, tanda ini dapat diklasifikasikan sebagai Dicent Sinsign.

\section{SIMPULAN}

Berdasarkan analisis semiotika Peirce, sistem tanda yang terdapat di pusat perbelanjaan bersifat deskriptif karena memang ditujukan untuk mendeskripsikan objek-objek sehingga secara khusus dan jelas terbedakan satu sama lain. Pembahasan yang telah dilakukan juga memperlihatkan bagaimana klasifikasi tanda-tanda yang berbeda mengimplikasikan efek yang berbeda-beda pula terhadap para pengunjung pusat perbelanjaan, sehingga para pengunjung tersebut dapat menempatkan diri mereka sesuai dengan konteks dalam mana mereka tengah berada. Kategori tanda yang berhasil diidentifikasi pada pusat-pusat perbelanjaan di antaranya Dicent Sinsign, Iconic Sinsign, Dicent Symbol atau Proposition, Dicent Indexical Legisign, Qualisign, dan Rhematic Indexical Legisign. Selain itu, hasil pembahasan juga menunjukkan bahwa klasifikasi Peirce bukanlah klasifikasi yang terpilah secara kaku. Satu tanda dapat saja memiliki karakteristik dari beberapa kategori yang berbeda sekaligus.

\section{DAFTAR PUSTAKA}

Ambar. (2017). Pengantar Ilmu Komunikasi - Sejarah - Hakikat - Proses. https://pakarkomunikasi.com/pengantar-ilmu-komunikasi

Budiman, Kris. (2005). Ikonisitas Semiotika Sastra dan Seni Visual. Yogyakarta: Buku Baik

Chandler, Daniel. (2002). Semiotics: The Basic. New York: Routledge Taylor and Francis Group

Gorlee, Dinda L. (1994). Semiotics and the Problem of Translation: With Special Reference to the Semiotics of Charles S. Peirce. Amsterdam: Rodopi.

Kintan Safira Maydi dan Diah Agung Esfaandiari. (2018). 'Analisis Semiotika Charles Sanders Peirce Pada Karya Video klip "Baby Shark" dalam mempromosikan citra pejabat daerah Bima Arya Sugiarto di Kota Bogor.' e-Proceeding of Management, 5(1): 1233-1250. https://core.ac.uk/download/pdf/299921343.pdf

Untung Yuwono dan Tommy Christomy. (2004). Semiotika Budaya. Depok: Pusat Penelitian Kemasyarakatan dan Budaya Direktorat Riset dan Pengabdian Masyarakat UI

Van Zoest, Aart \& Panuti Sudjiman. (1993). Serba-serbi Semiotika. Jakarta: Gramedia Pustaka Utama. 